\title{
Effects of Fitness on Anxiety among High School Students in Congo Summative Evaluation of Volleyball
}

\author{
Aristide Ewamela ${ }^{1,2}$, Paulin Mandoumou ${ }^{1,2}$, Euloge Moboza Ndongo ${ }^{1}$, Portejoie Jean Aimé Tsiama ${ }^{1}$, Marady Tobene \\ Tormian $^{2}$, Joachim Bongbélée ${ }^{1,2}$ \\ ${ }^{1}$ Institute on Higher Physical Education and Sports, Marien Ngouabi University, Brazzaville, Congo. \\ ${ }^{2}$ UNESCO Chair in Education Sciences, Marien Ngouabi University, Brazzaville, Congo. \\ Correspondence: Dr. Paulin Mandoumou, Institute Higher Physical Education and Sports, University Marien \\ NGOUABI (Congo-Brazzaville), PO Box : 1100 Brazzaville (Congo).
}

Received: February 29, 2016

doi:10.11114/ijsss.v4i6.1547
Accepted: March 14, 2016

Available online: April 13, 2016

URL: http://dx.doi.org/10.11114/ijsss.v4i6.1547

\begin{abstract}
The aim of this study was to evaluate the effects of physical fitness on anxiety during the summative evaluation of the volleyball cycle. To this end, 22 students from military school [experimental group (age 17,55 $\pm 0,51$ ans, size: 171,18 $\pm 2,28 \mathrm{~cm}$, weight $65,77 \pm 1,38 \mathrm{~kg}$, BMI: $22.46 \pm 0,72 \mathrm{~kg} \cdot \mathrm{m}-2$, speed-strength: 58,64 $\pm 2,82 \mathrm{~cm}$, cardiovascular index:

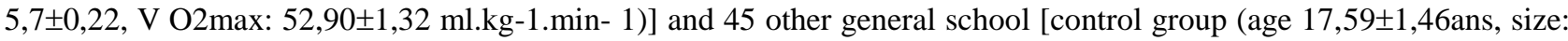



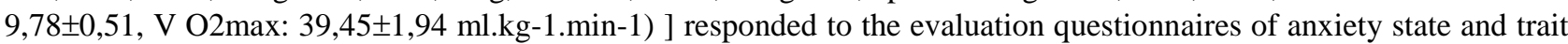
anxiety (Spielberger, 1975). The results have shown a higher state anxiety value in subjects in the experimental group compared to the control group $(51,27 \pm 5,17 \mathrm{Vs}$. $40,88 \pm 5,42)$ while the line anxiety is significantly reduced in subjects in the experimental group compared to the control group $(43,95 \pm 2,86$ Vs. $46,98 \pm 4,47)(\mathrm{P}<0,001)$. These results suggest that improved fitness increases anxiety state and parallel reduces trait anxiety during the summative evaluation of volleyball.
\end{abstract}

Keywords: Physical condition, summative, anxiety, Congolese students

\section{Introduction}

\subsection{Problem}

A study by Simon and Martens (1979) examines the anxiety of children during sports and non-sports related conditions and to individual groups. The selected activities in sport are: baseball, basketball, football, gymnastics, hockey, swimming, wrestling, and a school competition in physical education. Activities related to non-sporting variable, for their part, are: a school exam, a music solo performance and a musical performance group. This extensive study also deals with the anxiety of sports considered contactless and those with contacts.

However, the inaccessibility of subjects practicing volleyball in high schools in Brazzaville depends insufficient sports facilities, equipment and the weakness of teachers in the educational process of this activity (Ewamela and al., 2014). Research results show, in variable sports, individual sports and that contact was more anxiety (anxiety disorder) compared to individual sports noncontact sports teams with and without contact respectively.

The majority of the research conducted to assess the pre-competitive anxiety have used measures of trait anxiety, considering the outset that the trait was indicative of transitional anxiety in a specific situation. Furthermore, Passer (1982) mentions that laboratory and field studies did not indicate little significant difference in the state of anxiety of children before the competition, where trait anxiety had a more large fluctuation.

In the Republic of Congo, the Sports and Physical Education lessons were marked by hyperactivity and practitioners participating causing their recurring interruption. Thus, we ask the question:

1) How physical condition does affect the state of anxiety and trait anxiety among students during the summative evaluation?

This substance will be determined by the hypotheses, objectives and the interests of the study. 
This reflects psychological disorders that manifest anxiety in the students and Congo - Brazzaville is a concern that the substance will be determined by the hypotheses, objectives and interests of the study.

\subsection{Hypotheses and objectives}

To address this concern, we formulated the following hypothesis: the best physical condition increases anxiety state and trait anxiety decreased among high school students of Congo - Brazzaville.

By conducting this study we set the following objectives:

-Evaluate fitness;

-Evaluate anxiety state and trait anxiety;

-Review the influence of fitness on anxiety through anxiety state and trait anxiety.

\section{Method}

\subsection{Subjects}

\subsubsection{Characteristics}

The subjects of this study were all teenagers with ages and sizes respectively for the control group ( 17,59 $\pm 1,46$ years $170,95 \pm 1,26 \mathrm{~cm})$ and the experimental group $(17,55 \pm 0,51$ years and $171,18 \pm 2,28 \mathrm{~cm})$. These subjects were selected according to the criteria of the absence of medical cons-indication to sport practice, regularity during Physical Education, voluntary participation in various tests for evaluating fitness and filling cells of both anxiety questionnaires.

\subsection{Sampling Procedures}

These topics were selected by non-probability model based on empirical methods. To this end, it came from a volunteer sample used in medical or psychological experiments

\subsubsection{Sample Size, Power, and Precision}

The study involved 67 secondary school students divided into two groups, namely: experimental-group consists of 22 male students of the Military Preparatory School General Leclerc (MPSGL) subjected to two hours per week of Sports and Physical Training, two sessions of two forty minutes each drive in Volleyball as part of the school sports club, daily sessions of enlightenment through physical activity including walking, environmental maintenance activities (safety);

-group control comprising 45 male first students of the Lycée Pierre Savorgnan De Brazza (LPSB) subject to two weekly hours of Sports and Physical Training.

\subsubsection{Measures and covariates}

This study had of two parts, namely: assessing the physical condition and the extent of anxiety.

Physical fitness was assessed through the measurement of anthropometric characteristics and fitness.

The measured anthropometric characteristics were: age, which was raised on the specifications general information of students in classes held by the Sports and Physical Training teachers while the size and weight were measured according to the principle of the committee Kino QUEBEC reported by Leger (1985). The data on the size and weight were used to calculate body mass index (BMI) and determination of nutritional status according to the scale published by the World Health Organization (WHO) (2003):

$$
\begin{array}{ll}
\text { BMI }=\frac{W}{s^{2}} & \text { Weight }(\mathrm{kg}) \\
& \text { Size }(\mathrm{cm}) \\
& \text { BMI }\left(\mathrm{kg} \mathrm{m}-^{2}\right)
\end{array}
$$

Physical fitness was assessed through systems:

ATP / CrP (sargent Test)

Glycolytic (TestRufier Dickson);

Oxydative (Luc Leger test) (Billat, 2004).

Anxiety was assessed using two Speilberger questionnaires, one for anxiety and the other State for the trait anxiety (Spielberger, 1975).

The means of two groups were compared by the Student test always using the SPSS software. 


\section{Results}

\subsection{Recruitment}

The subjects of this study were recruited during the 2014-2015 school year, specifically during the holding volleyball cycle October 10 to 20 December 2014 for the two groups (control and experimental).

\subsection{Statistics and Data Analysis}

The mean and standard deviation were respectively the statistical indices of central tendency and dispertion used to present the results of this study. The hypothesis test used for comparison of means was that of student.

\subsection{Participants Flow}

At the beginning of the study, the experimental and control groups were formed respectively of 22 male students and 98 students including 58 boys and 40 girls. As boys in the control group, there were 3 exempt from STP classes, 10 irregular in these courses. As for the girls in the control group, there were 5 exempt from STP classes, 10 absolute irregular in these courses and 25 having an irregularity said during menstruation depending which is a cultural factor affecting women's activities in the collective life in Africa. Hence, 22 students in the experimental group and 45 students in the control group were considered as participants.

Age, height, weight, body mass index (BMI ) of subjects in the control group and the experimental group are shown in Table 1 as mean \pm standard deviation $(\bar{x} \pm \delta)$.

Table 1. Age, height, weight, body mass index (BMI) of subjects in the control group and the experimental group as mean \pm standard deviation $(\bar{x} \pm \delta)$

\begin{tabular}{lcccc}
\hline & Control group & Experimental group & \multicolumn{2}{c}{ Significance } \\
\cline { 2 - 5 } & $(\mathrm{n}=45)$ & $(\mathrm{n}=22)$ & $\mathrm{t}$ & $\mathrm{P}$ \\
\hline Age (years) & $17,59 \pm 1,46$ & $17,55 \pm 0,51$ & 0.16 & $\mathrm{NS}$ \\
Size $(\mathrm{cm})$ & $170,95 \pm 1,26$ & $171,18 \pm 2,28$ & 0.95 & $\mathrm{NS}$ \\
Weight $(\mathrm{kg})$ & $70,70 \pm 2,50 * * *$ & $65,77 \pm 1,38$ & 20.54 & $<0,001$ \\
BMI $\left(\mathrm{kg} \mathrm{m}{ }^{2}\right)$ & $24,19 \pm 0,50 * * *$ & $22,46 \pm 0,72$ & 7.20 & $<0,001$ \\
\hline
\end{tabular}

NS: no significant difference

*** Highly significant difference $(\mathrm{P}<0,001)$

A reading of Table I reveals that there is no significant difference between the ages and sizes of the subjects in both groups. However, the control group had significantly higher values of weight and BMI compared to those obtained in their counterparts in the experimental group $(\mathrm{P}<0,001)$.

The table 2 also present as mean plus or minus standard deviation $(\bar{x} \pm \mathrm{SD})$, strength-speed, cardiovascular index (LCI) and maximal oxygen consumption $\left(\dot{V} \mathrm{O}_{2} \max \right)$ of the control group and experimental group.

Table 2. Strength-Speed, Cardiovascular Index (ICV) and the Maximum Oxygen Consumption $\left(\dot{V} \mathrm{O}_{2} \max \right)$ of the Control Group and the Experimental Group as Mean \pm Standard Deviation $(\bar{x} \pm \delta)$

\begin{tabular}{|c|c|c|c|c|}
\hline & \multirow{2}{*}{$\begin{array}{l}\text { Control group } \\
\qquad(n=45)\end{array}$} & \multirow{2}{*}{$\begin{array}{c}\text { Experimental group } \\
\qquad(\mathrm{n}=22)\end{array}$} & \multicolumn{2}{|c|}{ Significance } \\
\hline & & & $\mathbf{t}$ & $\mathbf{P}$ \\
\hline Force-velocity (cm) & $46,07 \pm 1,19$ & $58,64 \pm 2,82 * * *$ & 52.38 & $<0,001$ \\
\hline Cardiovascular Index & $9,78 \pm 0,51$ & $5,7 \pm 0,22 * * *$ & 17 & $<0,001$ \\
\hline $\mathrm{V} \mathrm{O} 2 \max \left(\mathrm{ml} \cdot \mathrm{kg}^{-1} \cdot \mathrm{min}^{1}{ }^{1}\right)$ & $39,45 \pm 1,94$ & $52,90 \pm 1,32 * * *$ & 54.38 & $<0,001$ \\
\hline
\end{tabular}

***: Significant difference $(\mathrm{P}<0,001)$

It appears from the analysis of Table 2 as speed-strength of the experimental subjects was significantly greater compared to that of the control group $(\mathrm{P}<0,001)$. For cons, the ICV subjects in the experimental group were significantly lower than the issue of control group $(\mathrm{P}<0,001)$. However, the $\dot{V} \mathrm{O}_{2}$ max of subjects in the experimental group was significantly greater compared to that of the control group $(\mathrm{P}<0,001)$. 
Table 3 contains status values and anxiety trait anxiety subjects in the experimental group and the control group as mean plus or minus standard deviation $(\bar{x} \pm \delta)$.

Table 3. Anxiety state and trait anxiety subjects in the experimental group and the control group as mean \pm standard deviation $(\bar{x} \pm \delta)$

\begin{tabular}{lcccc}
\hline & control group & Experimental group & \multicolumn{2}{c}{ Significance } \\
\cline { 2 - 5 } & $(\mathrm{n}=45)$ & $(\mathrm{n}=22)$ & $\mathbf{t}$ & $\mathrm{P}$ \\
\hline Anxiety state & $40,88 \pm 5,42$ & $51,27 \pm 5,17 * * *$ & 43.29 & $<0,001$ \\
Trait of anxiety & $46,98 \pm 4,47 * * *$ & $43,95 \pm 2,86$ & 13.17 & $<0,001$ \\
\hline
\end{tabular}

$* * *$ : Significant difference $(\mathrm{P}<0,001)$

The values in this table indicated that subjects in the experimental group a significantly higher level of state anxiety and trait anxiety parallel one less than their counterparts in the control group $(\mathrm{P}<0,001)$.

\section{Discussion}

This study was conducted with the objective to evaluate the effects of physical fitness on anxiety during the summative evaluation of the volleyball cycle. Earlier this study, we hypothesized that: the best physical condition increases anxiety state and trait anxiety decreased among high school students Brazzaville. To this end, we used a cross method compared with measurements, testing and questionnaires. Volleyball as any physical activity is determined by several factors including physical condition. The results of this study show that both groups (experimental and control) have statistically identical ages and sizes (Table 1). However, weight and body mass index (BMI) of the control group were significantly larger compared to subjects in the experimental group $\left(70,70 \pm 2,50 \mathrm{KgVs}\right.$ and $65,77 \pm 1,3824,19 \pm 0,50 \mathrm{~kg} . \mathrm{m}^{2}{ }^{2} \mathrm{Vs}$ $22,46 \pm 0,72 \mathrm{~kg} \mathrm{~m} \mathrm{-}^{2} ; \mathrm{P}<0,001$ ) (Table 1). These weights and higher BMI subjects of the control group can be explained by their reduced physical activity. Indeed, the control group these subjects have only two hours of Physical Education (EPS) which does not allow them to use enough calories. These subjects accumulate calories they do not use enough, and that the extra calories turned to fat, making them heavy (Ewamela, 2005). However, the BMI of both groups show that they have a normal nutritional status (WHO, 2003). BMI is proportional to body weight, these subjects are predisposed to the practice of physical and sport activities (Vitassallo and al, 1988; Ewamela and al., 2006). Nevertheless, the experimental subjects being heavy month with lower BMI may have a better physical fitness.

Physical fitness encompasses the physical qualities, namely: strength, speed, endurance, flexibility, endurance, speed, strength-speed. The results reveal that the force-velocity group of subjects Experimental is significantly greater compared to that of the control group $(58,64 \pm 2,82 \mathrm{Vs} 46,07 \pm 1,19 \mathrm{~cm} \mathrm{~cm} ; \mathrm{P}<0,001)$ (Table 2). This force-velocity of the lower limbs of experimental subjects is dependent on specific motor staining volleyball (Bongbele et al., 1998) which constitutes the APSA their early specialization in addition to the physical activities in these establishment (two Weekly hours of Sports and Physical Education, daily sessions of enlightenment through physical activity including walking, environmental maintenance activities (safety). This high-speed strength of experimental subjects reflects practice regular, progressive, individualized that induces muscle contraction with a transient hypertrophy due to infiltration of plasma water in the muscle cell hyperplasia resulted in the duplication of muscle cells, hypertrophy associated with increased section and the number of muscle fibers (Wilmore and Costill, 2009). These physiological adaptations of muscle during exercise are likely responsible for the improved strength.

For cons, the ICV subjects in the experimental group was significantly lower than that of the control group $(5,7 \pm 0,22 \mathrm{Vs}$ $9,78 \pm 0,51 ; \mathrm{P}<0,001$ ) (Table 2). These results indicate improved cardiac recovery of experimental subjects reflecting the restoration of heart rate basal level following endurance training and rehydration (Craplet, 1986; Chandler and al., 1998; Ewamela et al, 2013). The best recovery is dependent on the reduction of resting heart rate is also due to the advanced mitigation and spontaneous barroreflexes gain and delay restoration of the sympathetic system. Rehydration is a model of fluid replacement and one of longer terms of the recovery (Commandré and al., 1988). Moreover, rehydration is known, reduces the thermal stress of physical effort in hot and humid atmosphere. Thus, the dehydration rehydration delays (BONGBELE and al., Op. Cit.) And attenuates secretion of catecholamine from which bradycardia. It has been reported in this regard that, rehydration is probably responsible for the reduction of catecholamine levels and heart rate after the completion of a task muscle (McArdle and al., 2001). This greater improvement in recovery in these experimental subjects can be explained by their working lives.

The recovery is closely linked to $\dot{V} \mathrm{O}_{2}$ max. The $\dot{V} \mathrm{O}_{2}$ max subjects in the experimental group was significantly greater compared to that of the control group $(52,90 \pm 1,32 \mathrm{ml} . \mathrm{kg}-1 . \mathrm{min}-1 \mathrm{Vs} 39,45 \pm 1,94 \mathrm{ml} . \mathrm{kg}-1 . \mathrm{min}-1$; P $<0,001)(\mathrm{Table} 2)$. Most large $\dot{V} \mathrm{O}_{2}$ max of experimental subjects is due to endurance training which they were subjected and rehydration. Endurance training is the best way to improve the $\dot{V} \mathrm{O}_{2} \max$ (Jones and al., 1999). This improved $\dot{V} \mathrm{O}_{2}$ max is proportional 
to the imposed workload (Lloyd and Cooke, 2000) resulting in overcharging. Ewamela (2005) Indeed, during the endurance work, subjects subjected to varying degrees of work leading to the principle of overload showed improvement $\dot{V} \mathrm{O}_{2}$ max. It may also explain the larger $\dot{V} \mathrm{O}_{2} \max$ of experimental subjects by the influence of the average length of breaks between periods of effort on cardiovascular adaptations and performance of physical activity (Samaja and al. , 1999). In view of the above, the experimental subjects have better fitness.

The physical condition affects anxiety subjects subjected to the practice of physical sports and artistic activities, specifically with the type of anxiety. The results are indicative of the greater value of state anxiety in patients in the experimental group compared to the control group $(51,27 \pm 5,17 \mathrm{Vs} 40,88 \pm 5,42 ; \mathrm{P}<0,001)$ (Table 3 ). This higher value of state anxiety is the consequence of the perceived threat of the summative evaluation associated with recurrent events among subjects in the experimental group. Indeed, these experimental subjects participating in meetings of the League of Volleyball Brazzaville department and sometimes are confronted with junior teams of that league and manifest the fear of losing. This fear is a threat whose perception can cause psychological fluctuations, including: anxiety state (Passer, supra; Scanlan and Lewthwaite., 1984.).

This higher value of the anxiety state is dependent on multiple factors derived from summative assessment, including: the psycho-social development associated with the construction of the character, social adjustment, emotional control, sportsmanship , respect for others, leadership, responsibility, self-discipline, self-confidence, self-expression, initiative, courage, cooperation, etc. We can also assign this value higher anxiety state at the age of subjects that do not allow them to bear the emotional burden of the summative evaluation applicant's competitive shape and exposing them to increasing the anxious state. Indeed, several groups of parents, educators and professionals have strongly criticized organized competitions, judging exaggerated focus on victory and disapproving the presence of a system of distorted values. They add that children experience emotional tension and an unnecessary pressure. Despite major developmental values related to competitions (Scanlan, 1978), some authors (Johnson \& McCutcheon, 1980) indicate that there is strong evidence showing the nuisance of anxiety in children and adolescents. Since competitive meetings have been in place for a long time, it seems more important to examine the conditions in which children are subjected during competitions to maximize the positive and minimize the negative effects rather than question their existence (Haubenstricker, 1976).

The highest state of anxiety in experimental subjects can be explained by the preponderance of technical elements volleyball. Volleyball is known, is a sports team of unquestionable technical wealth by elements such as: button, cuff, walking cons, diving ... These technical elements are individual tasks whose realization is anxiety. In this respect, the search for Simon and Martens (op. cit.) shows that the activities where performance was individually performed showed higher anxiety cues from subjects that performed in teams. This tendency to feel more anxiety in the individual activities is explained by an increased potential assessment in an individual performance (Martens, 1977; Smith, 1969).

On the contrary, the feature of anxiety was significantly reduced in subjects in the experimental group compared to the control group $(43,95 \pm 2,86 \mathrm{Vs} 46,98 \pm 4,47 ; \mathrm{P}<0,001)$ (Table 3$)$. This reduction related anxiety is related to fitness. Indeed, the practice of physical activity improves fitness and beneficial effects on the psychological level to the extent that it ensures the moral well-being, let go, fight against stress. It is a quality of welcome to "jump" psychological blocks, acceptance of changes in states and peer motivation. In effect, physical condition improves self-esteem in its overall appearance self-esteem overall dimensions) and physical (physical appearance, estimating the strength, speed, endurance and athletic skill) (Ewamela and al., in press). This self-esteem high value induces an expectation in the subject of sports competence and reduced her negative psychological effects, hence the low value of trait anxiety in these subjects in the experimental group with better fitness.

The reduced value of trait anxiety is due to the mix of effort that requires the practice of volleyball. The practice of volleyball we know is sometimes aerobic and anaerobic but sometimes aerobic depending on the length of meetings, hence the change of anxiety trait depending on the intensity of exercise. In this regard, it was reported that the practice of moderate walking for 10 weeks appears to be more beneficial on mood and stress management, the training exercises of strength and mobility (Steptoe, 1993). This reduction is mainly related anxiety related to the type of exercise. Indeed, the intense and moderate exercise causes a decrease in anxiety, as well as responsiveness pictures emotionally charged (Smith, 2002). Individuals with better fitness have the same initial stress responses but recover more easily (Tsai, 2004).

Reducing anxiety is dependant of aerobic activity (Broman-Fulks, 2004). In fact, individuals having a high sensitivity to anxiety exaggerate and interpret physiological sensations, which contribute to increase the panic attacks. The exercise that produces physiological responses identical to those of anxiety (eg, increased heart rate and respiratory) causes habituation to these stimuli and therefore a decrease in the associated fear. Aerobic exercise high intensity seems more effective than aerobic exercise in mild anxiety reduction (Broman-Fulks, op. Cit.).

The reduction of trait anxiety was due to strategies needed to team sports including volleyball. Especially the various collective sports practices require strategies. These strategies include: striking the ball hard at the right time to send the 
ball across the net, so that the opposing team cannot return it, the attack of the beautiful by the rear behind the line of $3 \mathrm{~m}$, unable to form one or more walls in defense, accurate services whose effective implementation is a source of anxiety reduction.

The reduction of trait anxiety is also due to the effects of visio motrices repetitions that constitute one of the educational tools. To this end, Weinberg and al. (1981) studying the effects of visual motor repetitions on relaxation and karate performance and on the line and the state of anxiety in adults practicing this sport (Weinberg and al., 1982) have shown that practice made of visual motor repetition does not improve performance but allows a reduction in anxiety (trait and state) in athletes (Weinberg and al., 1982).

The reduction the feature of anxiety can be explained by the sports experience of experimental subjects. Incidentally, Morgan (1980) noted those athletes (older) more experienced may be less affected by the stress than younger or less experienced; Beginners can have different anxiety levels of those with more experience. Smith (1983) reports a difference between anxiety star players (those who have been selected for an annual award) and substitute players (those participating in jousting was not regular and they had little experience) .

In sum, the results of this study have shown that individuals with better physical condition have a high state anxiety and the feature of anxiety reduced during the summative evaluation of volleyball.

\section{References}

Billat, V. (2004). Physiology and methodology of training: from theory to practice sports, Deboeck University Press , Brussels.

Bongbélé, J., Locko, C. A., \& Massamba, A. (1998). Influence of the position on the loss of body weight of Footballers in hot and humid atmosphere. Med. Sprt., 72(3), 130 - 134.

Broman-Fulks, J. J., Berman M. E., Rabian B. A., \& Webster, M. J. (2004). Effects of aerobic exercise on anxiety sensitivity. Behaviour Research and Therapy, 42, 125-36.

Chandler, M. P., Rodenbauch, D. W., \& Dicarlo, S. E. (1998). Arterielbarroreflex resting mediats post exercise reductions in arterielpresure and heart rate, Am. J. Physiol., 255(5), 1627-1634.

Commandre, F., Vanuxem D., Fornaris E., Khan, H. R., \& Vanuxem, B. P. (1998). Recovery: Biological, Med. Sport, 62, 29-32.

Craplet, C. P. (1986).Activities of sport physiology, Vigot, Paris, 539.

Ewamela A. (2005). Teaching EPS hot and humid environment: physiological disturbances and remediation models. Single PhD in Didactics of APS, UNESCO Chair in ENS Education Sciences for Central Africa, University Marien NGOUABI, Brazzaville 4

Ewamela, A., Empilo, S. M., Ndebani F., \& Massamba, A., Bongbélé, J. (2013).Effects of EPS cycles on cardiovascular respiratoires adjustments among college students Congolese Cahiers of the UNESCO Chair, 2, 70-83.

Ewamela, A., Empilo, S. M., Ndebani, F., Mankoko, L., \& Bongbélé, J. (2006). body composition during a school cross in hot and humid atmosphere, Africans Cahiers Science of Education, 5, 123-132.

Ewamela, A., Kena Lubika, A., Mandoumou, P., Itoua Okemba J., Lembe G., Entsiro F., Nkiama Ekisawa, C., \& Bongbélé J. perverse effects of teaching on the disengagement EPS students of humanities KINSHASA, conventionnées case of some Catholic schools. Cahiers of Gombe Institute of Education In Press)

Ewamela, A., Mviri, H. C., Entsiro, F., Mandoumou, P., Itoua Okemba, J., Lembe, G., Ibata, A., \& BONGBELE, J. (2014). Problem of teaching volleyball in high schools of the Congo Brazzaville. Review the rainy season of the Faculty of Letters and Human Sciences, 10, 273-281.

Haubenstricher, J. L. (1976). Stress hazards of competitive athletics. Osteopathic Annals, 5, 16-31.

Johnson, J. H., \& McCutcheon, S. (1980). Assessing life stress in older children and adolescents: preliminary findings with the Life Events Checklist. In 1. G. Sarason \& C. D. Spielberger (Eds.), Stress and Anxiety vol. 7. Washington D.C: Hemisphere.

Jones, A. M., \& McConnell, A. M. (1999). Effet of exercise modality on oxygen uptake during heavy exercise, Eur.J. Appl. Physiol., 83(3), 21.

Leger L. (1985). Evaluation kit fitness KINO -QUEBEC Committee, Issue B-6 , Ministry of recreation , hunting and fishing, QUEBEC .

Martens, R. (1977). Sport Competition Anxiety Test. Champaign, li., Human Kinetics. 
McArdle, K., \& Katch. (2001).Physiology Physical Activity. Energy, Nutrition, Performance, Vigot, Paris, 558.

Morgan, W. P. (1980). Personnality dynamics and sports. In SUINN R. M. (Ed), Psychology in Sports: Methods and Applications, Minneapolis, MN: Burgess, 145-155.

Passer, M. W. (1982). Psychological stress in youth sports. In MAGILL R. A., M. 1. Ash \& F. L. Smoll, Children in Sport: A Contemporary Anthology, Champaign, li.:Human Kinetics.

Samaja, M., Allibardi, S., Milano G., Neri G., Grassie B., Gladen B., \& Hogan, M. C. (1999). Differential depression of myocardial fonction and metabolism by lactate and $\mathrm{H}^{+}$, Am. J Physiol., 276(1), 3-8.

Scanlan, T. K. (1978). Social evaluation: A key developmental element in the competition process. In MAGILL R. A., ASH M. J., \& SMOLL F. L. (Eds.) Children in Sport: A Contemporary Anthology. Champaign, n.: Human Kinetics.

Scanlan, T. K., \& Lewthwaite, R. (1984). Social psychological aspects of competition for male youth sport participants: 1. predictors of competitive stress. Journal of Sport Psychology, 6(2), 208-226.

Simon, J. A., \& Martens, R (1979). Children's anxiety in sport and nonsport evaluative activities. Journal of Sport Psychology, 1(2), 160-169.

Smith, C. P. (1969). The origin and expression of achievement-related motives in children. In Smith C. P. (Ed.) Achievement Related Motives in Children. New York: Russell Sage.

Smith, T. (1983). Competition trait anxiety in youth sport: differences according to age, sex, race, and playing status. Perceptual and Motor Skills, 57(3), 1235-1238.

Spielberger, C. D. (1975). Anxiety: State-trait anxiety process. In SPIELBERGER C. D. \& SARASON I. G., Stress and Anxiety, vol. 1. (pp. 115-143). Washington, D.C.: Hemisphere Publ.

Steptoe, A., Kearsley, N., \& Waltyers, N. (1993). Cardiovascular activity during mental stress following vigorous exercise in sportsmen and inactive men. Psychophysiology, 30, 245-52.

Tsai, S. L. (2004). Audio-visual relaxation training for anxiety, sleep, and relaxation among chinese adults with cardiac disease. Research in Nursing and Health, 27, 458-68.

Vittassalo, I. T., Bosco C., Sauro, C., \& Montoneh, H. (1982). vertical Long jump : aerobic and anaerobic performance capacity of players to high-level Volleyball, FIVB, 5.

Weinberg, R., Seabourne, T., \& Jackson, A. (1981). Effects of visuo-motor behavior rehearsal, relaxation imagery on karate performance. Journal of Sport Psychology, 3, 238-328.

Weinberg, R., Seabourne, T., \& Jackson, A. (1982). Effects of visuo-motor behavior rehearsal on state-trait anxiety and performance: Is practice important? Journal of Sport Behavior, 5(4), 209-220.

Wilmore and Costill (2009) Physiology of Sport and Exercise .Bruxcelles :Deboeck University.

World Health Organization (2000). Obesity: preventing and managing the global epidemic. Report on a WHO Consultation on Obesity, Geneva, 3-5 June, 1997. WHO/NUT/NCD/98.1. Technical Report Series Number 894. Geneva: World Health Organization, 2000.

\section{(cc) $\mathrm{BY}$}

This work is licensed under a Creative Commons Attribution 3.0 License. 